\title{
Information and communication technology in agribusiness: A study of mobile applications in perspective of India
}

\author{
Chandan Gupta* \\ Department of Commerce, Graphic Era ( Deemed to be University), Dehradun (Uttarakhand), \\ India \\ Manu Gupta \\ Department of Mathematics, J. V. Jain College, Saharanpur (Uttar Pradesh), India \\ Pradeep Joshi \\ School of Management, Graphic Era Hill University, Dehradun (Uttarakhand), India \\ Ajendra Kumar \\ Department of Mathematics, Gurukula Kangri (Deemed to be University), Haridwar- 249404 \\ (Uttarakhand), India
}

${ }^{*}$ Corresponding author. Email: chandangupta@geu.ac.in

\section{How to Cite}

Gupta, C. et al. (2021). Information and communication technology in agribusiness: A study of mobile applications in perspective of India. Journal of Applied and Natural Science, 13(2), 766 - 774. https://doi.org/10.31018/jans.v13i2.2620

\begin{abstract}
Federation of Indian Chambers of Commerce and Industry in one of its finding in 2019 stated that about 58\% Indians are dependent on agriculture and agriculture sector make about $15.96 \%$ of India's GDP. To get the best agriculture inputs and best harvest price is the big question for Indian farmers; thus, we can say that "Agriculture is the foundation of the Indian economy". With the origin of Mobile Applications (m-apps) for agriculture and a huge dependency on Information and Communication Technology (ICT) in agribusiness, the scenario in rural India has been changing rapidly. Since India's economy depends mainly on agriculture, there is a lot of potential for Information and Communication Technology and mobile applications for agribusiness and its marketing. With growing smartphones with m-apps penetration in rural India, the agribusiness in rural belts of India is set for extension and further digitalization to revolutionize the agriculture sector. In recent years, nearly all Indian farmers possess a mobile, and 50\%are smartphones with internet connections. With Government's new legislative policy changes as the Digital India programme, mobile applications in India's rural belt cannot remain isolated. Digital India will connect rural Indians farmers worldwide through the internet and mobile applications and provide them with all necessary upliftment in agribusiness in India. This study has focused on the ICT and m-applications used in farming today and how they have changed agribusiness by providing a digital platform and with their impact on agribusiness.
\end{abstract}

Keywords: Agriculture, Agri-business, Digital Technology, Information and Communication Technology (ICT), Mobile Apps

\section{INTRODUCTION}

Agricultural m-commerce refers to the applications of mobile commerce (m-commerce) in the field of the agriculture sector for the supply-demand concept by use of internet network in the production, provides information services and other different operation in agriculture. Agricultural m-commerce also covers the cash flow of business transactions and physical flow of agricultural products. M-commerce in agriculture has helped in breaking the limit of region and time.(Singh and Kumar, 2018). It has increased information transmission, which helped farmers to lower transaction cost, reduce inven- tory and increase business opportunities.(Hellstrome and Troften, 2010). A conducive environment is being developed for the awareness of farmers in rural India through m-commerce for improving the quality of agricultural products and for the up-gradation of the industrial use of agriculture products. In India economy, agriculture serves as its backbone. About 58 per cent of the total Indian population rely on agriculture and agricultural products. The agriculture sector accounts for around 15.96 per cent of India's Gross Domestic Product (GDP). There is a huge scope to introduce and implement new technology to solve the challenges like weather unpredictability, scarcity of good quality seeds, 
pesticides, fertilizers and direct interaction with the markets to sell their crops after the harvest for farmers (Saravanan and Vincent, 2020). India is a country that has more than 600,000 villages, and connecting these rural areas with internet broadband will have a great impact. Indian Government is helping rural Indians through various ambitious campaigns like Electronic Governance (e-governance), digi-locker, e-basta etc. Through greater internet connectivity, our country can achieve a better economic status and mobile commerce growth in Agri sector for our farmers(Ansari and Pandey, 2013).

Digital India is one of the Pilot Indian governments Project which includes, connecting rural areas with highspeed internet connectivity. The change in the economic conditions of farmers in agribusiness is due to the rapid growth in Information and Communication Technology (ICT) and internet connectivity. In India's GDP agriculture sector is a major contributor with around $16 \%$ Contribution and this can be increased by providing farmers with better opportunities for their growth and welfare. Information related to agriculture practices internet is available to Indian Farmers today through various mediums, including mobile apps, agriculture helpline numbers, Agriculture sites on the internet, and farmers' portal. Consultation about weather forecasting in different seasons that includes specific knowledge is being available to farmers in their local language only by sending a registration message through their mobile phones. The specific knowledge includes weather reports, fertilizer information, seasonal pests, control measures, market prices, etc. (PRS Legislative Research, 2019-20). Thus the objective of this research are i) To study the need for ICT and mobile apps in the development of the agribusiness, ii) To study the Mobile Apps helping the Indian farmers in their agribusiness, iii) To study the impact of ICT and mobile apps on agribusiness.

In India, Radio broadcasts were started in the late 1950's. The first television-based program "Krishi Darshan" was initiated for framers in 1960's on Doordarshan. In addition Government of India took two good steps (1) The setup of community radio for the agriculture sector and (2) the setup of telecentres for agriculture sectors. (National Policy on Education, 1986)., in the report issued by the Department of Electronics and Information Technology, Government of India, revealed that now the time has come when India needs to be prepared for the Digital India campaign. Zook et al. (2004)) in their descriptive research, considered different current movements about mobile phones and internet connectivity in society. The researcher emphasized various mobility conditions that affect digital technology (wireless technologies), consisting of market standing, mobility and ease of usage. Ngai and Gunasekaran (2007) classified mobile commerce into five classes, namely, m-commerce concepts and usage (ii) wireless infrastructure, (iii) mobile interface, (iv) cellular user infrastructure and (v) m-apps and their types. The authors have further analyzed that emphasis is required to integrate the impact of culture on mobile commerce and laid emphasis on doing research in mobile banking and payment, which in turn would be helpful in not only agri-business but in every sector.

The traditional ICT's are important instruments to spread knowledge to the farmers about the scientific and technical in agricultural knowledge, leading to the adoption and use of new technologies. Through various studies, most farmers in India use various information sources like TV, radio, newspapers, traders, other farmers' opinions, relatives, agricultural extension services from the Government, and seed dealers for gaining information on agriculture (Mittal et al., 2010). Jamaluddin (2013) revealed that India had acknowledged a growth of e-commerce in the agricultural sector. He further explained that demographic transition today marks increased use of e-commerce by farmers due to increased technological advancement and easy access. He concluded that the internet is becoming more and more popular among people in agri business or related activities.

Kitturet al. (2016) explained about huge dependency on ICT in the agricultural input scenario. He revealed that the growth of mobile commerce and mobile commerce apps through smartphones in rural India is increasing, and through this agribusiness has shown revolutionized growth. Further, the study states that penetration of mobile phones in rural India has increased many folds. Nearly all the farmers have mobile phones, out of which $40 \%$ are smartphones, so there is a high potential reach. Through proper guidance, this can bring modernization in buying and selling agri inputs by the Indian farmers. He said that "Understanding m-commerce platforms that add value to the distribution channels for agri input is a main challenge" and another challenge is providing logistics without increasing the farmer cost and cash on delivery (COD) payments in rural areas.

Now, Mobile phones and bank accounts constitute the participation of rural India in Digital India Campaign and also focus on four major balusters (i) Establishment of broadband facilities for farmers in India (ii) Universal accessibility of farmers to mobile phones(iii) Mobile seva and (iv) Services based on intensive information, where there is a great need of research for different mobile-based information services. Various information services are to expedite which are based on mobile and various agri projects for rural farmers in India. Thus, it is emphasized that M-Commerce and mobile applications for rural farmers in India are not choice but essential.

The present study is descriptive and analytical as; an attempt is made to find the ICT and mobile apps in agri- 
culture development and analyze the impact of the same on the agri-business. This study will also include the most popular mobile apps used by Indian farmers in India. The data for the research has been collected through secondary sources like repost, surveys, research papers and websites etc., and an in-depth study has been made to answer the following research questions:

Do really there is a need for ICT and mobile apps in the development of the agriculture Business?

Which Mobile apps are developed and designed for Indian farmers? What type of information gap is filled by these Mobile apps and how they are helping farmers in their agri-business?

Do the ICT and mobile apps have an impact on agribusiness? What are the benefits provided by these to the Indian farmers?

\section{EMERGING NEED OF ICT \& MOBILE APPS FOR AGRICULTURE DEVELOPMENT}

After the green revolution call in the mid-sixties, there was no major technological development in our agriculture sector which could provide a new dimension to the agricultural sector for increasing its productivity. Inadequate extension services and very low access to information/inputs have widened the gap for the adoption of new technology that leads to poor agriculture productivity levels. Thus a push towards higher agricultural productivity today shall require an information-based/ ICT, agricultural decision-making system and often described as the next great evolutionary step in agriculture (Ngai and Gunasekaran, 2007). Adhiguruet al. (2009) reported that the farmers are now coming up with advanced information sources that help them reach new markets and provide good-quality commodities to consumers. Though there remains a certain challenge: i) Extending reach to timely information which is suitable for farmers, ii) Reaching to all rural farmers. Cyber extension and cell phone-based applications support these processes, i.e. ICT should involve, but it should be farmer-friendly. Farming/ agriculture is a tough and challenging sector in India, considering increasing water scarcity, land degradation, and complex climate and environmental changes.

The success is contributed by the factors like land condition, soil health, weather changes, knowledge about markets, inputs, support services, investment, and infrastructure. So the solutions to the problems faced by the farming sector have to be flexible in terms of local needs and considering the diversity of the Indian agriculture sector. This can be done through the correct use of ICT considering diversity in India (Tripathi et al., 2012). Science of Delivery for improving the agriculture sector in India requires digitally active farmer organizations, better functioning, ICT enabled service providers and farmers friendly institutional framework (Seth and Ganguly, 2017).

India's IT industry is sourcing about $67 \%$ of the US market, but India lacks agri-technology with a robust ICT network. (Organisation for Economic Co-operation and Development, 2019-2028). ICT in India has great potential and there is a need for ICT in the agriculture sector for a positive impact on agricultural performance and enhance farmers' income (Chhachharet al., 2014). Today Indian farmers are facing challenges of degrading and diminishing natural resources, declining production, growing demand for agri product both in terms of quantity and quality, less income, climate changes and many more. Therefore, technology adaptation is needed to make farmers know about the latest modern technology to overcome the challenges (Emerick et al., 2016). By overcoming these challenges, the farmer will learn about the increased yield of crops and reduce crop failure and uniform annual return. The major crops in India have low production yield as compared with those in other world countries per hectare, so to respond to the growing need both domestically and globally, it must be ensured that our farmers should produce more for which the farmers in India are not technologically advance (Organisation for Economic Cooperation and Development, 2019-2028).

For a farmer, the pre-harvesting stage of crop requires proper selection of crop. Its input like the seed, soil productivity, getting credit and insurance, and digital technology could be very useful to recommend about the said pre-harvesting works. On-farm stage, farmers require information about weather conditions and crop disease and pest and weed related information, which could be ICT enabled again. And lastly, at the postharvest stage, farmers require data of domestic market consumption and export markets and hence the adoption of digital technology is required. (Tripathi et al., 2012). Thus, for Indian farmers, these digital solutions are imperative, and application and innovation need to be exploited. Data generation about agriculture knowledge and its advanced analytics of the application of digital technology in agriculture promote and allow farmers to make the best decisions about their need and take advantage of the economical use of inputs and labour. Some direct applications of digital technology include GIS (geographic information systems), RS (remote sensing via satellites), soil health monitoring, crop production and livestock and farm management etc., in the digital revolution for farmers in the local language. This revolution will help supply chains to increase quality, integrate traceability, ensure continuous supply, and be competitive globally (Seth and Ganguly, 2017)

Besides the above-said facts, another major challenge for Indian farmers is the lack of market access which leaves them with middlemen to negotiate who offer 
them less price for their own profit and farmers get lower prices for their yield and even lose out on sales if middlemen do not buy their product. As a result, many farmers fail to provide good food for their children, family members and themselves. In India, farmers are more vulnerable to the impacts of economic crises and climate change. Small farmers in India put in long hours of work for getting a good harvest but are hampered by different factors which include having only a small marketable surplus to sell, dependence on middlemen and local traders, low market rates for their harvest and not enough access to storage facilities (cold storage etc.) (Ferroni and Zhou, 2012).

It was observed that increasing mobile phone penetration and mobile-enabled information services in rural India could help reduce the lack of information in agriculture-related concepts and complement extension services (Tripathi et al., 2012). Thus a transition is need of the day and is required at each level. This transition should be from the lower level of the system to the higher level of the system. Changes should be ICT enabled that could be helpful for our growth of the agriculture sector properly considering the diversity of the Indian agriculture sector.ICT/ digital revolution could enable farmers to get information about various agricultural practices and transparency on market prices. Also, through the IT-enabled revolution, Indian farmers can advertise their produce, machinery and goods directly to buyers. Though many IT applications are now available, India lacks behind (Emerick et al., 2016). Interesting patterns are observed in Indian farmer's usage for different ICT sources about agriculture knowledge and extensions. In India, the percentage of farmers who have access to new agriculture technology and digital technology amounts to around $40 \%$ of all Indian farmers. It increases as per the farm size. Mass media, Agri-input dealers and technological savvy modern farmers are the most important information source and they also advise all other farmers. In contrast, cooperatives and purchasers play a smaller but vital role. The live demonstrations by Government agencies, small fairs, study tours for farmers and KrishiVigyan Kendra farm science centres are also of utmost importance for crofters in India. (Saravanan and Vincent, 2020). India's government present policy for agriculture is mainly focused on encouraging new innovation in agriculture and agriculture entrepreneurship and out-of-box thinking to achieve higher growth and greater income security for the farmers and agriculture sector. The shrinking of the landholdings has reduced the dependence of Indian population on agriculture, resulting in farmers' low per capita income. Thus, people should move out of agriculture, which can only be possible by the digital revolution in the agriculture sector. New innovations have to emerge in the agriculture sector that could make it fast-track earning sector for people involved in this. These days in India, global changes are being observed in the agriculture sector like liberalized market, enriched farmers and commercial enterprise based on intensive information.

\section{Mobile Apps for agriculture development in India:}

Dissemination of Information related to agriculture to farmers of India who are considered to be the poorest communities is now made easier by the proliferation of mobile phones and mobile apps usage. With the advancement of technology and penetration of mobile phones in India's rural region, mobile apps and services are also being exclusively designed for farmers to fulfil the larger objective of empowering farmers' which facilitates the extension services that can address the global food security issues (AgriApp: Smart Farming App for Indian Agriculture). Most popular mobile apps developed and used by Indian farmershave been studied (retrieved from the various websites: play.google.com, mkissan.gov.in, krishijagran.com, agrifarming.in and (Saravanan and Vincent, 2020) etc. and most commonly used Agri Mobile Apps are:

\section{Agri Bazar}

Coming with the slogan "Empowering millions to feed billions" Agri Bazar was started in 2016 by providing an online platform for interconnection between farmers, agri-traders, banks, various enterprises and Government. In addition, an award-winning wallet AgriPay was developed in 2017 to facilitate transactions. At present times it offers Artificial intelligence-driven knowledge, analytics, and crop advisory and more on a click. It has over 1 lakh user and Rs. 14000 crore Gross Merchandise Value (GMV) on their digital platform and has a mission to empower small farmers through technology using Artificial Intelligence (AI), Machine Learning (ML), big data, Internet of Things (IOT) and drone drones (https://play.google.com/store/apps/details?id=co m.agribazaar.android\&hl=en_IN\&gl=US).

\section{Agri App}

AgriApp is a mobile application based on an Android platform greatly beneficial to the farming community. Its features include providing detailed information on smart farming for Crop Production, Crop Protection from weeds, pest and climate change other allied services for agriculture. This App offers sustainable technology for both ecology and economy using the features like IOT, Big-Data, ICT and e- Commerce in a short time in agri sector and providing all farming solutions. AgriApp fills the gap between farmers and required accurate knowledge about Agricultural information and enables farmers to have high-efficiency technology-enabled agriculture harvest and marketing of the harvest 
(https://www.agriapp.co.in).

\section{AgriCentral}

This App has vision "Smart farming for all" and is specially made for the Indian agriculture sector for the benefits of Indian farmers helping them in taking critical decisions for their farming business to increase their profits and it uses state of art technologies like Global positioning (GIS), satellite imagery (Remote Sensing), big data analytics and image analytics (https:// play.google.com/store/apps/details?id=com.globalagr icentral\&hl=en_IN\&gl=US).

\section{Krishify}

It is an agriculture app used for farmers to discuss their crop issues, issues about soil and seeds, agriculture equipment, different GOI yojana like PMKisanYojana etc. In this App farmers can post videos and photos, get personalised feedback and suggestions on irrigation management, fertilizers, seed varieties, and other agriculture-related topics by agriculture experts and improve crop growth ( https://www.krishify.com).

\section{Krishi Network}

It is one the foremost Agriculture App for Indian Kisan and has Largest Network of Progressive Farmers trusted by Indian farmers. This App provides an effort to increase Indian farmers' income by linking them with progressive farming and market access via the internet and providing them advice from experts about growing dhan, tamatar, bajra, jwar, makka, protection using various types of fungicides etc. (https://krishinetwork.com). Updates about organic farming, agriculture inputs like fertilizers to use, agribusiness, pesticides details and seed procurement, weather and mandi rates (mandibhav), the latest information from the Department of Agriculture \& Kisanyojana like PM KrishiSinchayee Yojana, Soil Health Card, Crop Insurance etc. are available on this App. This App. is quite useful for Uttar Pradesh and Madhya Pradesh farmers as it contains news and information about these states.

\section{AgroStarKisan Helpline}

It is a "Made in India" app for Indian farmers for the following uses of farmers in India (https://

play.google.com/store/apps/details?

id=com.ulink. agrostar\&hl=en\&gl=US).

- Farmers talk (Krishi Charcha)

- Weather Forecasting

- Crop Information (basically in Gujarat, Maharashtra and Rajasthan)

- AgroStarAgri-Shop (basically in Gujarat, Maharashtra and Rajasthan)

Specially designed for rural India, this App is available in 11 regional languages, namely :(1) Hindi (2) Gujarati (3) Marathi (4) English(5)Tamil (6) Telugu(7) Malaya- lam (8) Kannada (9) Punjabi (10) Oriya and (11) Bangla. It has a very small App size, i.e. 4.3 MB and works offline both in $2 \mathrm{G}$ and $3 \mathrm{G}$ (what you visit is available in offline mode) and is maintained by a team of expert agri-doctors (AgroStar's 'Agronomy Centre of Excellence (ACE)).

\section{BharatAgri}

BharatAgri known as Agri Doctor App helps Indian farmers increase their crop yield and income and provide solutions on smart agriculture techniques. This App helps farmers reduce the cultivation cost by providing useful insights about various fields related to agriculture and increasing their crop harvest by adding their farm to their App. BharatAgri provides digital crop advisory and helps farmers with Soil Testing, regular farming tips, and the latest news in the agriculture sector and works on a set of advanced algorithms related to agriculture and modern technology that considers various parameters like soil \& water parameters and climatic conditions as well ( https://bharatagri.com).

\section{BigHaat}

It is an Agriculture App whose aim is to make agriculture more profitable. Among different agriculture platform in India, BigHaat is the largest agriculture platform providing agriculture solutions to the farmers / Kisan at their places using the latest agriculture technology and techniques for Indian farmers. It provides a platform for transparent, competitive and quality services to farmers by exposing them to several major input suppliers and buyers, which helps to improve their operational efficiency and productivity. BigHaat is in expansion mode with the leading brands of horticulture, agro-chemicals and nutrients to help Indian farmers to expand their horizon (https://play.google.com/store/apps/details? id=com.BigHaat\&hl=en_IN\&gl=US).

\section{PusaKrishi}

Developed by IARI(Indian Agriculture Research Institute), this App was launched in 2016 by the then Union Agriculture Minister. It aims to help farmers get information about technologies that will help increase productivity and income to farmers. The application provides Indian farmers information about new varieties of crops developed by ICAR (Indian Council of Agriculture Research). It also helps farmers increase their know-how about resource conservation, cultivation practices and farm machinery, which helps farmers get good returns ( http://www.mkisan.gov.in/download mobileapps.aspx).

\section{Kheti-badi}

It is a social initiative App that can be accessed in four languages, namely Gujrati, Hindi, Marathi and Eng- 
lish, and it aims to promote and support organic farming. It provides information to farmers regarding hazards of genetic modification in seeds, fertilizers used, chemical pesticides and assists farmers to switch from synthetic farming to organic farming (https://play.google.com/store/apps/details? id=com. app.khetibadi\&hl=en_IN\&gl =US).

\section{Plantix Partner}

Plantix Partner app is exclusively developed for Indian Agri-Retailers and provides the best solution for generating the demand and supply of products for agri-input in India. Plantix Partner provides the best rates to the agri-input retailer and he can purchase the agriproducts directly from top brands in that product. He can order pesticides, seeds and herbicides with the help of this mobile App-simply. The agri-input retailer has to choose the required agri input or product and select the quantity; the net rates will be visible to him immediately (https://plantix-partner.com/en/).

\section{FarmBaba}

This is a One-stop shop for farming products. FarmBaba is also a mobile app designed to provide services in gardening, food processing, purchase of agriculture machinery, dairy farming, agriculture, and purchase of manure and seeds. This application helps farmers compare the selling prices with the market rates and provides an extensive range of products related to the above services that could be easily sorted out with the help of choosing categories along with the easy return policy and secured free online payments ( https:// farmbaba.com).

\section{IFFCO Kisan}

This is one of the most popular app developed for the Farming Community. This App is exclusively dedicated to farmers of India, which helps farmers or Kisaan collect information related to their need by surfing the customized agricultural information through App and take informed decisions. This Kisan suvidha app, i.e., IFFKO Kisan App, provides the latest prices of agri-products in mandi ( MandiBhav) and provides information related to the weather forecast, animal Husbandry, horticulture along with advisory services related to agriculture and gives best practices tips related to agriculture. It connects the farmers and customers of their crops by providing a common platform and also provides news related to agriculture and new government schemes for them in 11 Indian languages in two modes,i.e. text and agriculture audio clip to make the farmers most comfortable to understand the information in their own language (Saravanan and Vincent, 2020).

\section{eNAM}

eNAM app (National Agriculture Market) is a mobile app promoted by the Government of India which provides an electronic platform connecting existing mandis and a common national market is created for agricultural products. This App facilitates information about the prices quoted by the remote traders and also provides access to arrivals and other related information to farmers on their smartphones. This App was implemented by the SFAC (Small Farmers Agribusiness Consortium) under the support of the Ministry of Agriculture and Farmers' Welfare, Government of India. This App provides a transparent auction process on the quality produce (agriculture commodities). The eNam also helps in the timely online payment by providing online market platforms for pan-India trade in agriculture products (https://enam.gov.in/web/mobile-app).

The other Indian agriculture app like Mandi Central, Apnikheti, DehatKisan, Kisanrath, Krishikisan and NaPanta etc. are also playing a vital role in the agriculture sector.

\section{IMPACT OF MOBILE APPLICATION AND ICT IN AGRICULTURE}

Mobile commerce has given the power to Indian agriculture and helps to establish market linkages, overcome productivity stagnation, and enhance farm management. The impact of mobile technology has improved access to the whole world and unlocking values for the people who are considered to exist at the bottom of the pyramid.

Looking at the growth of the agriculture sector from 2014 to 2019, there has been a very high fluctuation. It shows a growth of $6.1 \%(0.2 \%$ in $2014-15$ to $6.3 \%$ in 2016-17) and then a decline of $3.5 \%$ (6.3\% in 2016-17, and then declined to $2.8 \%$ in 2019-20). There has been a decrease of $1.7 \%$ in Gross value added from 2014 to 2019 as it was $18.2 \%$ in $2014-15$ and $16.5 \%$ in 2019 20. The above share has been declining on account of relatively higher growth performance of non-agricultural sectors, which shows that still the agriculture sector has to perform more efficiently and has to show more rigorous performance. Therefore, there is more need for advancement, and mobile commerce could be one of the major tools that can add to this major objective of this sector as it could help explore new markets and connect farmers to buyers. It can also help execute their number of functions with a simple tool in their hands, and that is mobile. (PRS Legislative Research2019-20).

Despite the declining trend in the last three years, this sector has also attracted leading Information technology companies, young innovators, some big investors and large conglomerates in India. It has paved the way for the rapid development of the ecosystem and digital solutions. By the year 2022, it is expected that the global market size will reach US $\$ 6.34$ billion with an annual 
growth rate of $13.09 \%$. India and china expect a fast annual growth of $18.29 \%$ until 2022 but behind Northern America in the agriculture sector (Organisation for Economic Co-operation and Development, 2019-2028). With the advancement of technology, the farmers' service delivery has improved through effective market linkages for improved service delivery and can also find the highest price for their produce through e-Nam Mobile Application. ITC E-Choupal is going to shift to the mobile platform by mid-2019. The company has given it the name e-choupal 4.0 as already e-Choupal has empowered the farmer by providing internet kiosks in villages. Now the installation has reached the figure of about 6,100 , covering over 35,000 villages and serving over 4 million farmers and this initiative will move the farmers to initiate the new plug and play ready digital platform for agri-startups to build and expand their businesses.(Indian Tobacco Company, 2018).

Mahindra and Mahindra (M\&M), an Indian company, is leading producers of tractors and farm types of equipment. It has also launched a mobile app "Trringo" which helps the farmers take tractors on rent shows that mobile commerce has helped farmers use machinery without making large investments (https:// www.mahindra.com/stories/tringo).

Tata Consultancy Services (TCS) offers several services through its $\mathrm{mKRISHI}$ platform, aiming to broadcast best farming practices to each farmer. The increasing numbers of mobile phone users in rural regions of India have paved the way for the development of various mobile-based applications by government departments, entrepreneurs, and the private sector that have contributed a lot to the development of the Agriculture sector (Tata Consultancy mKRISHI Platform, 2009).

In the present scenario, ICTs can make a radical change in agriculture in rural areas. The new mobile apps related to Krishi(agriculture) has come with great innovations. These applications help farmers to collect relevant information on advanced agriculture practices, quality inputs, helps in reducing stress and most importantly, know about the tendencies of the market (Hellstrom and Troften, 2010). Through these applications, farmers can sell their products online using their smartphones. Smartphones and mobile applications have come with great innovations. ICT has transformed agriculture in Indian rural area, and farmers are improving skills, experience and sales through their smartphones using social media, mobile apps and websites. Applications of smartphones provide the solution for agriculture development and helping Indian farmers to have access to knowledge and information about agriculture extension work and advisory services. Mobile applications are being developed, which is helping Indian farmers in reducing stress, acquiring information on agriculture practices, getting weather and climate information, input, markets trends etc. (Mittal et al., 2010). The mobile phone and m-apps had created economic benefits for the farmers, and these impacts are classified in three ways: (i) easy access to agriknowledge, (ii) Mobility and (iii) convenient and timesaving. Thus Mobile phones applications serve by providing farmers communication mode and access to the knowledge/information service in their farmland (Mittal et al., 2010). The role and impact of ICT and mobile applications are mentioned in Table 1.

\section{Future opportunities}

There is great potential through Agri mobile apps to support the Indian farmers' community and improve their livelihoods. The study presented has explained that mobile phones and agri business application act as catalysts to improve farmers' productivity, incomes, and information, which is timeliness and trustworthiness and is helping to meet their needs and expectations. But still, there are so many things which can improve the agriculture sector as a whole in India .some of the key factors that need to be addressed are:

Mobile phone portability and flexible content delivery capability for two way communication at low-cost delivery and providing specialised solutions.

Farmers should get information delivery at their convenient time and place of their choice through the mobile phone revolution in rural India.

Mobile Agri applications should provide information in the regional/national language as required by the farmers for core functionalities and relevant information.

The Agri mobile applications should run on multiple platforms like Windows, Android and iOS in both mobile

Table 1. Various roles and impact of mobile application and ICT in Agri-business.

\begin{tabular}{|c|c|}
\hline Aims & Procedure \\
\hline $\begin{array}{l}\text { Education and } \\
\text { awareness }\end{array}$ & $\begin{array}{l}\text { Information about good practices, } \\
\text { improved crop varieties and pest or } \\
\text { disease management are provided } \\
\text { through mobile phones to farmers } \\
\text { and extension agents. }\end{array}$ \\
\hline $\begin{array}{l}\text { Commodity prices } \\
\text { and market infor- } \\
\text { mation }\end{array}$ & $\begin{array}{l}\text { Makes available regional market pric- } \\
\text { es for inform decision making } \\
\text { throughout the entire agricultural pro- } \\
\text { cess. }\end{array}$ \\
\hline Data collection & $\begin{array}{l}\text { Contains Applications which collects } \\
\text { data from large geographic regions }\end{array}$ \\
\hline $\begin{array}{l}\text { Pest and disease } \\
\text { outbreak }\end{array}$ & $\begin{array}{l}\text { Dissemination and collection of data } \\
\text { on outbreaks. }\end{array}$ \\
\hline
\end{tabular}

Source: Hellstrom and Troften (2010) 
and tablet versions to allow for greater technology transfer.

Initially, basic features required for agriculture practices must be free for every agri mobile application, but advanced or customizable features can be given to them later on a minimal chargeable basis.

The Agri mobile application version should be a standard one and our Indian farmers should be well informed and trained for mass usage and acceptability, which could be through demonstration videos for easy visibility.

Thus, to sum up, the impact of mobile applications and ICT, it is stated that it has provided the following benefits to Indian farmers:

Better access to Agri knowledge, e.g. about best agricultural practices, climate changes and weather forecasts Better access to market prices and farmer have a direct connection with buyers/ suppliers

Communication and efficiency have improved in the agricultural supply path

Middleman commission, losses and Fraud have drastically reduced.

\section{Conclusion}

The potential for invention and innovation through ICT and mobile apps in agriculture is huge and growing day by day. Still, various shortcomings are needed to overcome and only then, immense opportunities can be created in agribusiness for the farming community. The digital revolution in India has enabled and created an environment for farmers using these technologies provided by both the public and private sectors. It is observed that a key factor in adopting such technologies is pricing which, if subsidized, could be adopted by Indian farmers. It was also observed that the use of the mobile application by farmers through smartphones is very limited and there is a need to analyse it. There are many agri mobile applications today in India but the use of these applications and their roles must be promoted extensively amongst the farmers through e-literacy schools required to be set up by Government and our agri mobile application industry. In addition, it was found that through agri mobile applications, it is easier for buyers to assess the quality and quantity of the produce and benefit farmers by helping them to sell their products directly to buyers. Smartphone-enabled mobile applications for agriculture also facilitate the collection of large quantities of information in the form of data, which includes information on weather change, local climate, production, farming practices (soil health, seeds etc.) and rates (mandibhav). Though the mobile phones are increasing among the farming community in India and adaptation to information services is continuing deeper into rural productivity, achieving full potential depends on reducing other factors that affect the use of information by farmers through their mobile phones/

\section{smartphones.}

\section{Conflict of interest}

The authors declare that they have no conflict of interest.

\section{REFERENCES}

1. Adhiguru, P., Birthal, P. S. \& Kumar, B. G. (2009). Strengthening pluralistic agricultural information delivery systems in India. Agricultural Economics Research Review, (22), 71-80.

2. Ansari, M. A. \& Pandey, N. (2013). Assessing the potential and use of mobile phones in agriculture. Karnataka Journal of Agricultural Science. (26), 388-392.

3. Chhachhar, A. R., Qureshi, B., Khushk, G. M. \& Ahmed, S. (2014). Impact of information and communication technologies in agriculture development. Journal of Basic and Applied Scientific Research, 4(1), 281-288.

4. Emerick, K., De Janvry, A., Sadoulet, E. \& Dar, M. H. (2016). Technological innovations, downside risk, and the modernization of agriculture. American Economic Review, 106(6),1537-61.Available at: https://www.aeaweb.o rg/articles?id=10.1257/aer.20150474.

5. Ferroni, M., \& Zhou, Y. (2012). Achievements and challenges in agricultural extension in India. Global Journal of Emerging Market Economies, 4(3), 319-346.

6. Hellstrom, J., \&Troften, P. E. (2010). The innovative use of mobile applications in East Africa. Swedish International Development Cooperation Agency, Published by Edita, 2010.

7. Indian Tobacco Company (2018). ITC e-Choupal 4.0 by mid-2019; shift to mobile platform, handholding of agristartups key. Business Today, 24 Dec 2018. Retrieved from, https://www.itcportal.com/media-centre/press-repor ts-content.aspx $\mathrm{id}=2074$ \&type=C\&news $=$ ITC-e-Choupal-4 -0-by-mid-2019-shift-to-mobile-platform

8. Jamaluddin, N. (2013). Adoption of e-commerce practices among the Indian farmers, A survey of Trichy District in the State of Tamilnadu, India. Procedia Economics and Finance, (7), 140-149.

9. Kittur, N., Jain, R. \& Kittur, P. (2016). Potential of MCommerce of Agricultural Inputs in Kolar, Karnataka, India.Research Journal of Recent Sciences, 5(7), 1-10.

10. Mittal, S., Gandhi, S. \& Tripathi, G. (2010). Socioeconomic impact of mobile phones on Indian agriculture. Working paper No. 246. Retrieved from,https:// www.econstor.eu/handle/10419/176264\#: :text=The\% 20study\%20found\%20 evidence\%20that,which\%20contrib ute $\% 20$ to $\% 20$ productivity $\% 20$ enhancement.\&text=As $\%$ 20 mobile $\% 20$ penetration $\% 20$ continues $\% 20$ to,produc tivity\%20impact\%20in\%20the\%20future.

11. National Policy on Education (1986). National Policy on Education, 2-189. Retrieved from http://mhrd.gov.in/sites/ upload_files/ mhrd/files/document-reports/POA_1992.pdf

12. Ngai, E. W. \& Gunasekaran, A. (2007). A review for mobile commerce research and applications. Decision Support Systems, 43(1), 3-15.

13. Organisation for EconomicCo-operation and Development (2019-2028). Agricultural output growth to keep food prices low over the coming decade, but many uncertainties are ahead, OECD-FAO Agricultural Outlook 2019-2028, 
Retrived from, https://www.oecd.org/agriculture/oecd-faoagricultural-outlook-2019/

14. PRS Legislative Research (2019-2020). Report summary, Economic Survey 2019-20, PRS Legislative Research. Retrived from https://www.prsindia.org/report-summaries/ economic-survey-2019-20\#: :text=Agriculture $\% 20$ and $\%$ 20allied\%20activities,of\%20GVA\%20in\%202017\%2D18.

15. Saravanan, R. \& Vincent, A. (2020). Agricultural Extension and Advisory Systems in Tamil Nadu. Working Paper 3, MANAGE Centre for Agricultural Extension Innovations, Reforms and Agripreneurship, National Institute for Agricultural Extension Management (MANAGE), Rajendranagar, Hyderabad, India.

16. Seth, A. \& Ganguly, K. (2017). Digital technologies transform- ing Indian agriculture. The Global Innovation Index, 105-111

17. Singh, A. \& Kumar, M. (2018). Impact of M-Commerce on Agriculture. International Journal of Advanced Research and Development,3(2), 342-345.

18. Tata Consultancy mKRISHI Platform (2009). Enabling digital farming with pride . Retrieved from, https:// www.tcs.com/enabling-digital-farming-with-pride

19. Tripathi, A. M., Singh, A. K., \& Kumar, A. (2012). Information and communication technology for rural development. International Journal on Computer Science and Engineering, 4(5), 824.

20. Zook, M., Dodge, M., Aoyama, Y. \& Townsend, A. (2004). New digital geographies: Information, communication, and place. Geography and Technology, 155-176. 